\title{
Impact of insurance precertification on neurosurgery practice and health care delivery
}

\author{
Richard P. Menger, MD, MPA, ${ }^{1,2}$ Jai Deep Thakur, MD, ${ }^{1}$ Gary Jain, MD, ${ }^{3}$ and Anil Nanda, MD, MPH ${ }^{1}$ \\ 'Department of Neurosurgery, LSU Health Shreveport, Louisiana; ${ }^{2}$ Harvard University John F. Kennedy School of Government, \\ Cambridge, Massachusetts; and ${ }^{3}$ Department of Surgery, Mayo Graduate School of Medicine, Rochester, Minnesota
}

\begin{abstract}
OBJECTIVE Insurance preauthorization is used as a third-party tool to reduce health care costs. Given the expansion of managed care, the impact of the insurance preauthorization process in delaying health care delivery warrants investigation through a diversified neurosurgery practice.
\end{abstract}

METHODS Data for 1985 patients were prospectively gathered over a 12-month period from July 1, 2014, until June 30, 2015. Information regarding attending, procedure, procedure type, insurance type, need for insurance approval, number of days for authorization, or insurance denial was obtained. Delay in authorization was defined as any wait period greater than 7 days. Some of the parameters were added retrospectively to enhance this study; hence, the total number of subjects may vary for different variables.

RESULTS The most common procedure was back surgery with instrumentation (28\%). Most of the patients had commercial insurance $(57 \%)$ while Medicaid was the least common (1\%). Across all neurosurgery procedures, insurance authorization, on average, was delayed 9 days with commercial insurance, 10.7 days with Tricare insurance, 8.5 days with Medicare insurance, 11.5 days with Medicaid, and 14.4 days with workers' compensation. Two percent of all patients were denied insurance preauthorization without any statistical trend or association. Of the 1985 patients, 1045 (52.6\%) patients had instrumentation procedures. Independent of insurance type, instrumentation procedures were more likely to have delays in authorization $(p=0.001)$. Independent of procedure type, patients with Tricare (military) insurance were more likely to have a delay in approval for surgery $(p=0.02)$. Predictably, Medicare insurance was protective against a delay in surgery $(p=0.001)$.

CONCLUSIONS Choice of insurance provider and instrumentation procedures were independent risk factors for a delay in insurance preauthorization. Neurosurgeons, not just policy makers, must take ownership to analyze, investigate, and interpret these data to deliver the best and most efficient care to our patients.

https://thejns.org/doi/abs/10.3171/2016.5.JNS152135

KEY WORDS health care economics; insurance preauthorization; Medicare; Medicaid; neurosurgery practice delivery

$\mathrm{I}$ NSURANCE preauthorization is used as a third-party evaluation tool to reduce health care costs prior to procedure reimbursement. ${ }^{8}$ It allows the insurance companies to evaluate and control the amount and timing of medical care administered under their payment structure. ${ }^{28}$ However, substantial physician and ancillary staff time is spent dealing with preauthorization status. Work loss secondary to time spent dealing with preauthorization is estimated at $\$ 23$ to $\$ 31$ billion dollars annually. ${ }^{5}$ With the advent of the Affordable Care Act, it is estimated that the proportion of adults without insurance will fall to about 10\%; it has fallen from 18\% in 2013 to $13.4 \%$ in May 2014. ${ }^{1}$ Given the expansion of managed care, the impact of the insurance precertification process will only grow in the near and distant future. This will have a dramatic economic impact as well as a substantial impact on the interpersonal relationship between physician and patient.

Neurosurgery procedures are especially vulnerable to this process given their high upfront cost. This is combined with advanced complex procedures that can lead to protracted stays in the intensive care unit. For example, laminectomies cost $\$ 77,000$ for quality-adjusted life year and spinal fusions resulted in $\$ 115,000$ per quality-adjusted life year gained. ${ }^{22}$ Surgery for degenerative spondylolisthesis can result in long-term cost savings as opposed to nonoperative care, but insurance companies are not 
necessarily structured to see that return. Of Americans with employer-based private insurance, $12.8 \%$ will switch carriers, while nearly half of those who shopped in the Obamacare marketplaces will switch plans. ${ }^{11,24}$ This creates an emphasis for maximum immediate cost saving, which can place the insurance company at odds with the patient/society's long-term medical goals. It can create dissociation between value, principal, and agent.

Here, we evaluate the insurance preauthorization process through a diversified neurosurgery practice by investigating procedural and insurance-based factors related to delays in insurance preauthorization.

\section{Methods}

Data for 1985 patients were prospectively gathered across 6 different neurosurgical providers (all affiliated with LSU) in various disciplines over a 12-month period from July 1, 2014, until June 30, 2015. A prospective database collection was performed on consecutive bases for all patients requiring a surgery during that time period. Included patients were only considered on an outpatient basis as seen through the neurosurgical clinic. Emergent cases and hospital consultation requiring immediate, same-day hospitalization, or in-house surgical procedures were not considered in this study. By definition, patients who did not have any insurance coverage and were seen in our free care clinic did not undergo the same review process. Patients presenting to our Veterans Affairs clinic were also not included in the study. Information regarding attending, procedure, procedure type, insurance type, need for insurance approval, number of days for authorization, or insurance denial was obtained. Delay in authorization was defined as any wait period greater than 7 days.

Information was taken from neurosurgeons with practices specializing in skull base surgery, open vascular surgery, general neurosurgery, minimally invasive spine surgery, functional neurosurgery, and pediatric neurosurgery. All patients scheduled for neurosurgical procedures who presented through the outpatient clinic were considered for this study regardless of attending, surgical procedure, or hospital location. Data from neurointerventional faculty were intentionally omitted, given the breadth of procedures performed outside of the typical neurosurgery practice pattern.

ANOVA, chi-square, and regression analyses were used as appropriate. Initial analysis of categorical variables was done using the Pearson chi-square test, and those that signified a trend were put in binomial multivariate regression analysis to determine the odds ratio, confidence interval, and $\mathrm{p}$ value. Comparison of means across more than 2 groups of insurance was done using ANOVA or KruskalWallis testing.

\section{Results}

A total of 1985 patients underwent evaluation for insurance preauthorization for surgical intervention (Table 1). The most common surgery was back surgery with instrumentation (28\%) while the least common were kyphoplasty/vertebroplasty (1\%) and wound washouts $(0.5 \%)$.
TABLE 1. Type of procedure

\begin{tabular}{lc}
\hline \multicolumn{1}{c}{ Procedure } & No. of Patients (\%) \\
\hline Cranial & $281(14)$ \\
\hline Back surgery w/o instrumentation & $399(20)$ \\
\hline Back surgery w/ instrumentation & $557(28)$ \\
\hline Anterior neck surgery w/ instrumentation & $437(22)$ \\
\hline Posterior neck surgery w/o instrumentation & $22(1)$ \\
\hline Posterior neck surgery w/ instrumentation & $50(2.5)$ \\
\hline Peripheral nerve & $26(1.5)$ \\
\hline Functional & $158(8)$ \\
\hline Kyphoplasty/vertebroplasty & $19(1)$ \\
\hline CSF diversion & $31(1.5)$ \\
\hline Wound washouts & $5(0.5)$ \\
\hline
\end{tabular}

Overall, the type of procedure did not result in any statistical association with a denial of authorization $(p=0.40)$. However, the type of procedure made a significant difference in insurance authorization being delayed $(\mathrm{p}=0.002)$. Of these 1985 patients, 1489 (75\%) underwent spine procedures; this was not significantly related to a delay in authorization ( $\mathrm{p}=0.68)$. However, 1044 of 1985 patients $(52.6 \%)$ underwent instrumentation procedures, and this was significantly associated with increased delay in authorization $(\mathrm{p}=0.002)$.

Table 2 lists the different types of insurance held by the patients. Most of the patients had commercial insurance (57\%), while Medicaid was the least common (1\%). Across all neurosurgery procedures, insurance authorization, on average, was delayed 9 days with commercial insurance, 10.7 days with Tricare insurance, 8.5 days with Medicare insurance, 11.5 days with Medicaid, and 14.4 days with workers' compensation. Kruskal-Wallis testing found statistically significant differences among the average day delay in preauthorization for procedure based on different insurance types. Of patients with commercial insurance, $27.5 \%$ had a delay in authorization; $3.8 \%$ of Medicare patients had a delay, while $20 \%$ of patients with Medicaid funding had a delay in authorization. Of patients with Tricare, $45 \%$ had a delay of authorization, while patients with workers' compensation had a delay in $18.75 \%$ of cases.

Binary regression illustrated that instrumentation procedures and military insurance represented independent risk factors for a delay in authorization. Instrumentation for a procedure $(\mathrm{p}=0.001)$ and military insurance $(\mathrm{p}=$ 0.02 ) had increased chance at a delay in the surgery. Medicare insurance was protective against a delay in approving surgery in 40 of the 1985 patients $(\mathrm{p}=0.001)$. The multivariable analysis is found in Table 3.

Two percent of all patients were denied insurance preauthorization without any statistical trend or association.

\section{Discussion}

To our knowledge, our study is the first to provide prospective broad neurosurgical data regarding the numerical figures behind the insurance preauthorization process affecting actual patients. Our findings are substantial in that they illustrate a relationship between delays in authoriza- 
TABLE 2. Type of insurance

\begin{tabular}{lc}
\hline \multicolumn{1}{c}{ Insurance } & No. of Patients (\%) \\
\hline Commercial & $1129(57)$ \\
\hline Medicare & $736(37)$ \\
\hline Medicaid & $20(1)$ \\
\hline Military & $68(3.4)$ \\
\hline Workers' compensation & $32(1.6)$ \\
\hline
\end{tabular}

tion and both type of service provided and insurance type. The relevance of this in neurosurgery moving forward will only increase as managed care and alternative payment methods become more popular amid the backdrop of health care reform.

\section{Administrative Process}

The insurance precertification process places a significant burden on patients and physician practice. Physicians in midsize surgical practices spend an average of 2.3 hours a week dealing with insurance companies. Nurses in the same practice type combine for approximately 23.1 hours per week, while clerical staff will spend 41.8 hours per week working with insurance companies for any reason. ${ }^{5}$ Per year, the estimated cost to the surgical practice is $\$ 76,429$ of physician payment, $\$ 26,391$ in nursing staff time, and $\$ 29,118$ in clerical staff time. ${ }^{5}$ In the family practice setting, this cost burden ranged from \$2161 to \$3430 in lost work hours specifically for time spent dealing with the preauthorization prcoess. ${ }^{20}$ This serves as an important spoke in the wheel of health care reform. Across all specialties, administrative burdens continue to rise, accounting for $25.3 \%$ of hospital expenditures in 2011 in the US. As a point of reference, the next highest country was the Netherlands at a substantially lower $18.3 \% .^{13}$

The US operates on a market-based indirect consumer purchasing power system, which leads to companies attempting to maximize profit while individuals maximize usage of resources with third-party payment. This has unfortunately resulted in the payer, the insurer, attempting to control cost, sometimes at the expense of patient care.

\section{Examining the Preauthorization Process}

Physicians are upset about the duplicative burden placed on them by both private and governmental insurance. Nearly $43 \%$ of physicians view the administrative system of private insurers unfavorably, and $50 \%$ viewed Medicare unfavorably. ${ }^{9}$ Yet, many major commercial carriers require automatic preauthorizations for many procedures.

Focus on preauthorization should be placed on evidence-based guidelines related to the application of new technology. For example, clear repeated evidence does not support the use of routine full-body CT scans by healthy individuals younger than 30 years, and the FDA actively recommends against its routine use..$^{12}$ The radiation dosing from an annual full body CT scan, aside from any further unnecessary diagnostic imaging, creates a lifetime cancer mortality of $1.9 \% .^{3}$ Therefore, it is logically reasonable that insurance companies should not financially supple-
TABLE 3. Multivariate analysis for factors affecting delay in surgery*

\begin{tabular}{|c|c|c|c|}
\hline Outcome: Delay in Surgery & $p$ Value & $\operatorname{Exp}(B)$ & $95 \% \mathrm{Cl}$ for $\operatorname{Exp}(\mathrm{B})$ \\
\hline Instrumentation & $0.001 \dagger$ & 0.663 & $0.522-0.843$ \\
\hline Commercial insurance & 0.384 & 0.670 & $0.272-1.651$ \\
\hline Non-military insurance & $0.022 \dagger$ & 3.268 & $1.187-8.998$ \\
\hline $\begin{array}{l}\text { Government vs nongovern- } \\
\text { ment insurance }\end{array}$ & 0.967 & 0.971 & $0.236-3.995$ \\
\hline Medicare vs rest & $0.001 \dagger$ & 6.740 & $2.106-21.569$ \\
\hline
\end{tabular}

ment this type of testing. However, this becomes difficult when outcome and value are not easily quantified, such is the situation when dealing with back pain-related lumbar instrumentation cases. The focus should rest on data.

The American Association of Neurological Surgeons and the Congress of Neurological Surgeons Joint Spine Section has promulgated guidelines for instrumentation for degeneration without spondylolisthesis based on the best available data. Emphasis is placed on Class III evidence supporting the use of instrumentation in patients with documented instability on movement radiographs. There is also Class III support for fusion secondary to iatrogenic instability secondary to facetectomy in lateral stenosis cases. ${ }^{23}$ This should enter into the insurance companies' rubric for spinal instrumentation approval. When the guidelines are properly applied, insurance companies must consider the scientific evidence as it relates to the plan of care developed with the patient's personal neurosurgeon.

Another frustration with the managed care model is that it can undermine physician morale and the patientphysician relationship without clinical benefit..$^{14}$ Malik et al. illustrated that the advent of insurance preauthorization did not ensure improved compliance and appropriate use of criteria in cardiology procedures. ${ }^{15}$ After $100 \%$ preauthorization was required for multiplanar perfusion imaging, cost and time demands for the cardiology practice increased, while the positive predictive value of the procedure against the gold standard catheterization procedure did not increase.

Indeed, globally, goals for cost containment have resulted in delays in care rendered. Following a one-payer system in Canada, scoliosis spinal surgeons noted an average wait time of 24 months for surgery. As the pathology worsened, surgeons noted that this significantly increased the complexity of disease, operative time, blood loss, and hospital length of stay as compared with those patients off the waitlist. ${ }^{19}$ This represents a delay in care, burden on the patients, cost to the physician practice, and a possible delay to full return to the workforce. Reform needs to focus on the delicate balance between access and cost.

\section{Procedure Type}

Spinal instrumentation surgery has been increasing; intuitively, it makes sense for insurance companies to target 
high-volume, high-cost procedures with varying results. Medicare payments for spinal surgery doubled from 1992 to 2003 , with the rate of lumbar fusion increasing $500 \% .{ }^{27}$

The economic data are mixed. In the long-term, delaying instrumentation surgery in the preauthorization stage may not benefit an expedited return to the workforce. Back pain causes a significant reduction in missed workdays with $4.6 \%$ of 30,074 patients with chronic back pain missing at least 1 workday over the course a year. Back pain is the second most common condition leading to loss of workdays, after headache, losing on average 5.2 hours a week due to pain..$^{25}$ Return to work has also been expedited postoperatively with the advent of minimally invasive procedures. ${ }^{1}$ Patients undergoing minimally invasive transforaminal lumbar interbody fusion showed statistically significant reductions in narcotic use and quicker returns to the workforce. ${ }^{21}$ This consideration needs to factor into the preauthorization decision matrix. However, insurance companies do not necessarily see the prolonged returns, with up to $12.8 \%$ to $50 \%$ of patients switching private carriers annually.

The goal for neurosurgeons and insurance companies should be the proper implementation of best practice medicine in the best-selected patient cohort. Here, the importance of clinical databases is worth mentioning. The National Neurosurgery Quality and Outcomes Database can help establish risk-adjusted national benchmarks for quality care. This can be used to help guide, select, and predict which patients with which clinical conditions can have the best possible outcome and maximum beneft. ${ }^{2}$

\section{Insurance Type}

Tricare is the military's insurance system. Tricare military insurance provides medical care to approximately 10 million beneficiaries. Only about 1.8 million beneficiaries are active duty military. The rest are family members of military personnel and military retirees. ${ }^{10}$ Tricare beneficiaries have recently experienced tremendous frustrations in the delivery of their care through the purchased care system in the private sector. Only $64 \%$ of beneficiaries had an overall satisfactory experience..$^{18}$

A previous study also indicated that military patients are subject to delays and difficulty in obtaining access to care in the private sector. Overall, nearly $85.3 \%$ of civilian patients surveyed stated they received care quickly. Meanwhile, $78.2 \%$ of Department of Defense patients thought they were seen in a quick and efficient manner. ${ }^{18}$ Due to the bureaucratic process, the military notes that only $53 \%-84 \%$ of military beneficiaries are able to see a specialist within 28 days. ${ }^{18}$ The same commission noted that the average commercial insurance patient will only wait 18.5 days to see a specialist. ${ }^{18}$

This delay is partly the result of the Congress' 1991 mandate that lowered Tricare reimbursements to providers. Tricare often pays less than commercial insurance and even Medicare. Tricare usually reimburses $10 \%-15 \%$ less than Medicare. In certain instances, it can be $20 \%$ less than Medicare reimbursement. ${ }^{18}$ As a result, nearly $31 \%$ of beneficiaries had difficulty finding a civilian provider who accepted the military's Tricare insurance. ${ }^{18}$

Our data add another layer to the foundation of frustra- tions within the Tricare system. After obtaining approval and finding a provider, nearly $45 \%$ of Tricare patients in our study still had a delay in approval for surgery. This delay is frustrating for both patient and physician. Tricare's goal is to provide health care to military members, retirees, and their families to maximize the mission of the military. Therefore, the military's budget sees a double impact when procedures are delayed in active duty military personnel. The organization pays the direct cost of the procedure as well as the indirect reduction in the workforce. For example, in a military series, Tumialán et al. noted a direct cost of anterior cervical discectomy and fusion (ACDF) for radiculopathy to be $\$ 10,078 .{ }^{26}$ Correspondingly, the posterior cervical foraminotomy had a direct cost of $\$ 3570$. However, more important to the military was the indirect cost in return to the workforce. Patients undergoing ACDF were delayed in return to unrestricted active duty by 14.8 weeks more than those undergoing posterior cervical foraminotomy. This additional time away from work created an additional indirect cost of $\$ 13,586$ to $\$ 24,045$ in the ACDF group, with the total cost (indirect plus direct) ranging from $\$ 20,094$ to $\$ 30,553$ greater in the ACDF group. This cost difference and earlier return to active duty create even more of an incentive for the military to expedite approval for appropriate surgery.

\section{Protective Effect of Medicare}

Our series illustrated the protective effect of Medicare. Only $3.8 \%$ of Medicare patients had a delay. This is likely due to the nature of Medicare as a passive insurance; that is, Medicare does not actively negotiate on behalf of constituents for pricing with individual physicians or physician groups. Moreover, the majority of care is not administered in a managed format. Rather, it is an administrative pricing scheme determined by a complex rubric of a fee schedule related to the Healthcare Common Procedure Coding System. ${ }^{17}$ The exception to this is Medicare Advantage or Medicare Part C. In this structure, the patient's hospital (Part A), physician (Part B), and sometimes drugs (Part D) are managed by a capitated model through a private company. Medicare will pay the private company a fixed fee per patient per month of enrollment. ${ }^{16}$ This creates an obvious alignment for the insurance company to extract value from services purchased. It reduces moral hazard and works to prevent overuse of services. It creates preauthorization within Medicare.

However, Medicare Advantage did not have as much an impact in our series. In the parishes (counties) immediately surrounding our practice, Caddo Parish had 19\% Medicare Advantage enrollment and Bossier Parish had $16 \%$. The average enrollment of Medicare Advantage among Medicare beneficiaries in the United States is $33 \%$. The overall Louisiana average is $30 \%$ according to the Kaiser Family Foundation (http://kff.org/medicare/stateindicator/enrollees-as-a-of-total-medicare-population/).

It is important to realize that the payment of traditional Medicare will undergo a metamorphosis in the near future and this protective effect may erode. Medicare reimbursement is moving away from a strictly fee-for-service payment for services rendered model. By 2016, 30\% of payments in Medicare Part B (to physicians) must com- 
prise alternative payment methods or population-based payment. By 2018, this shifts to 50\% of all Medicare Part B payments. ${ }^{6}$ This will have a significant impact on the delivery of neurosurgical care. Alternative payment methods are still volume driven but will generate much more oversight on the delivery of neurosurgical care from outside entities. This includes accountable care organizations (ACO), medical homes, and the use of bundled payments.

In the future, the neurosurgeon will likely have to prove or justify the value of services rendered. Population-based payment will not be triggered by delivery of a service; rather, it will be strictly linked to each "insured person" captured. ${ }^{6}$ Both decisions will likely shift to a system with more oversight on the delivery of neurosurgical care.

\section{Workers' Compensation}

Patients receiving workers' compensation had the longest wait time of 14.4 days. This was not surprising, given the litigious nature of the workers' compensation system. Workers' compensation procedure approval and payment require a complex system of navigation between insurance company, employer, and provider. It is different from the standard insurer-provider relationship. As such, these types of cases made up only $1.6 \%$ of the elective surgery caseload.

\section{Affordable Care Act, Medical Loss Ratio, and Managed Care}

The Affordable Care Act supplied the private medical insurance carriers with more customers but with greater regulation and a prescribed medical loss ratio (MLR) ceiling at $80 \%$ (individual) to $85 \%$ (midsize/small group) for non-self-insured carriers. ${ }^{4}$ This influx of new patients into the private insurance market has also created the need for protection against unfair selection. As such, reinsurance, risk corridors, and risk adjustment provided greater equity among insurance companies. Reinsurance provides funding for insurance companies when unusual high claims cost occurs. Risk corridors limit an insurance company's losses and gains. Risk adjustment transfers funds from low-risk plans to higher risk plans. ${ }^{7}$ The goal is to take away the incentive for insurance companies to only select healthy patients.

Reinsurance and risk corridor protection are set to expire in 2016. This leaves risk adjustment as the sole means by which to protect insurance companies from costly patient selection issues. It remains unseen what role this might play in denials and preauthorization issues. With profits limited by the MLR and the increased future risk for adverse selection, it might create the need to generate higher margin per patient. It might force the insurer to more rigorously challenge perceived overuse of the system. Providers, in theory, benefit from the high MLR. It implies that more premium money is delivered to provider unit prices than insurance company profit.

Conversely, the majority of major insurance carriers currently generate procedure lists that require automatic preauthorization. This is likely to remain unchanged amid insurance reform. It is also important to remember that many large employers are self-insured and as such are not subject to MLR considerations. Focus could be on streamlining a more efficient and deliberate preauthorization system.

What goes relatively unmeasured is the commercial insurance benefit from the discouragement effect related to the physician practice work burden associated with delaying or denying care. There is a real disincentive for the physician to pursue questionable or borderline cases. It is unlikely that patient behavior would be altered by this rubric for procedures like surgery. It might play more of a role in other ancillary services. Furthermore, it is hypothesized that a delay of any kind can allow more capital investment of income from the insurance company per a period of time during the delay. This remains hypothetical and unlikely, as the margin gain from short-term capital investment may be immaterial.

\section{Limitations}

This study reports data collected in a prospective fashion from a group of neurosurgeons in the same geographic area. The specific information regarding individual cases and reasons for delay were not provided on individual accounts. Furthermore, the attribution of a delay being 7 total days is admittedly arbitrary, but it is patient centered and intuitively justified. The concept rested on the fact that a patient has a right to know whether the clinical decision made between the doctor and the patient would be honored within 1 week's time. Longer than this is an unreasonable burden on the patient.

\section{Conclusions}

Choice of insurance provider was statistically significantly related to delays in precertification with Tricare insurance that showed a mean delay of 10.7 days, with $45 \%$ of cases delayed at least 1 week to preauthorization $(\mathrm{p}=$ 0.02). Instrumentation procedures were also shown to be an independent factor in the delay of precertification regardless of insurance type $(p=0.001)$. Meanwhile, Medicare insurance was protective against having a delay in authorization for surgery.

\section{References}

1. Adogwa O, Parker SL, Bydon A, Cheng J, McGirt MJ: Comparative effectiveness of minimally invasive versus open transforaminal lumbar interbody fusion: 2-year assessment of narcotic use, return to work, disability, and quality of life. J Spinal Disord Tech 24:479-484, 2011

2. Asher AL, McCormick PC, Selden NR, Ghogawala Z, McGirt MJ: The National Neurosurgery Quality and Outcomes Database and NeuroPoint Alliance: rationale, development, and implementation. Neurosurg Focus 34(1):E2, 2013

3. Brenner DJ, Elliston CD: Estimated radiation risks potentially associated with full-body CT screening. Radiology 232:735-738, 2004

4. Brill S: America's Bitter Pill: Money, Politics, Back-Room Deals, and the Fight to Fix Our Broken Healthcare System. New York: Random House, 2015

5. Casalino LP, Nicholson S, Gans DN, Hammons T, Morra D, Karrison T, et al: What does it cost physician practices to interact with health insurance plans? Health Aff (Millwood) 28:w533-w543, 2009

6. Centers for Medicare \& Medicaid Services: Better care. Smarter spending. Healthier people: Paying providers for 
value, not volume. CMS.gov Newsroom. January 26, 2015. (https://www.cms.gov/Newsroom/MediaReleaseDatabase/ Fact-sheets/2015-Fact-sheets-items/2015-01-26-3.html) [Accessed June 22, 2016]

7. Centers for Medicare \& Medicaid Services: Reinsurance, Risk Corridors, and Risk Adjustment Final Rule. (https:// www.cms.gov/cciio/resources/files/downloads/3rs-final-rule. pdf) [Accessed June 22, 2016]

8. Committee on Hospital Care: Precertification process. Pediatrics 106:350-350, 2000

9. Commonwealth Fund: Primary Care Providers' Views of Recent Trends in Health Care Delivery and Payment. (http://www.commonwealthfund.org/publications/issuebriefs/2015/aug/primary-care-providers-views-deliverypayment) [Accessed June 22, 2016]

10. Congressional Budget Office: Approaches to Reducing Federal Spending on Military Health Care. (https:// www.cbo.gov/sites/default/files/113th-congress-2013-2014/ reports/44993-MilitaryHealthcare.pdf) [Accessed June 22, 2016]

11. Cunningham PJ: Few Americans switch employer health plans for better quality, lower costs. NIHCR Research Brief No. 12. National Institute for Health Care Reform. January 2013. (http://nihcr.org/analysis/improving-caredelivery/prevention-improving-health/health-plan-switching/) [Accessed August 23, 2016]

12. Food and Drug Administration: Full-body CT scans - what you need to know. FDA.gov. (http://www.fda.gov/RadiationEmittingProducts/RadiationEmittingProductsandProcedures/ MedicalImaging/MedicalX-Rays/ucm115340.htm) [Accessed June 22, 2016]

13. Himmelstein DU, Jun M, Busse R, Chevreul K, Geissler A, Jeurissen P, et al: A comparison of hospital administrative costs in eight nations: US costs exceed all others by far. Health Aff (Millwood) 33:1586-1594, 2014

14. Jauhar S: Why doctors are sick of their profession. Wall Street Journal. August 29, 2014. (http://online.wsj. com/articles/the-u-s-s-ailing-medical-system-a-doctorsperspective-1409325361) [Accessed June 22, 2016]

15. Malik B, Mikolich JR, Dhingra A, Lisko J, Mikolich B: Effect of third party payor pre-authorization policy on concordance of nuclear stress perfusion imaging and coronary arteriography. J Am Coll Cardiol 61:E1548, 2013 (Abstract)

16. Medicare.gov: How do Medicare Advantage plans work? (https://www.medicare.gov/sign-up-change-plans/medicarehealth-plans/medicare-advantage-plans/how-medicareadvantage-plans-work.html) [Accessed July 5, 2016]

17. MedPAC: Physician and Other Health Professional Payment System. (http://www.medpac.gov/documents/ payment-basics/physician-and-other-health-professionalspayment-system-14.pdf) [Accessed June 22, 2016]

18. Military Compensation and Retirement Modernization Commission: Final Report of the Military Compensation and Retirement Modernization Commission. (http://mldc. whs.mil/public/docs/report/MCRMC-FinalReport-29JAN15HI.pdf) [Accessed June 22, 2016]

19. Miyanji F, Newton PO, Samdani AF, Shah SA, Varghese RA, Reilly CW, et al: The impact of surgical waitlist times on scoliosis surgery: the surgeon's perspective. Spine (Phila Pa 1976) 40:823-828, 2015

20. Morley CP, Badolato DJ, Hickner J, Epling JW: The impact of prior authorization requirements on primary care physicians' offices: report of two parallel network studies. J Am Board Fam Med 26:93-95, 2013
21. Parker SL, Lerner J, McGirt MJ: Effect of minimally invasive technique on return to work and narcotic use following transforaminal lumbar inter-body fusion: a review. Prof Case Manag 17:229-235, 2012

22. Rajaee SS, Bae HW, Kanim LEA, Delamarter RB: Spinal fusion in the United States: analysis of trends from 1998 to 2008. Spine (Phila Pa 1976) 37:67-76, 2012

23. Resnick DK, Choudhri TF, Dailey AT, Groff MW, Khoo L, Matz PG, et al: Guidelines for the performance of fusion procedures for degenerative disease of the lumbar spine. Part 10: fusion following decompression in patients with stenosis without spondylolisthesis. J Neurosurg Spine 2:686-691, 2005

24. Sanger-Katz M: High rate of shopping and switching in Obamacare plans is a good sign. New York Times. February 26, 2015. (http://www.nytimes.com/2015/02/27/upshot/highrate-of-shopping-and-switching-in-obamacare-plans-is-agood-sign.html?_r=1) [Accessed July 5, 2016]

25. Stewart WF, Ricci JA, Chee E, Morganstein D, Lipton R: Lost productive time and cost due to common pain conditions in the US workforce. JAMA 290:2443-2454, 2003

26. Tumialán LM, Ponton RP, Gluf WM: Management of unilateral cervical radiculopathy in the military: the cost effectiveness of posterior cervical foraminotomy compared with anterior cervical discectomy and fusion. Neurosurg Focus 28(5):E17, 2010

27. Weinstein JN, Lurie JD, Olson PR, Bronner KK, Fisher ES: United States' trends and regional variations in lumbar spine surgery: 1992-2003. Spine (Phila Pa 1976) 31:2707-2714, 2006

28. Yee CA, Borba PS, Coomer N: Impact of Preauthorization on Medical Care in Texas. Cambridge, MA: Workers Compensation Research Institute, 2011

\section{Disclosures}

The authors report no conflict of interest concerning the materials or methods used in this study or the findings specified in this paper.

\section{Author Contributions}

Conception and design: Menger, Nanda. Acquisition of data: Menger, Thakur, Jain. Analysis and interpretation of data: Menger, Thakur. Drafting the article: Menger, Thakur, Jain. Critically revising the article: Menger, Thakur, Jain. Reviewed submitted version of manuscript: all authors. Approved the final version of the manuscript on behalf of all authors: Menger. Statistical analysis: Menger. Administrative/technical/material support: Nanda. Study supervision: Nanda.

\section{Supplemental Information}

\section{Previous Presentations}

This paper was presented as a digital poster at the 83rd AANS Annual Scientific Meeting in Washington, DC, May 2015. It was awarded 2nd place in the socioeconomic poster section.

\section{Correspondence}

Richard Menger, LSU Health Sciences Center-Shreveport, Department of Neurosurgery, 1501 Kings Hwy., PO Box 33932, Shreveport, LA 71130-3932. email: richard.menger@gmail.com. 